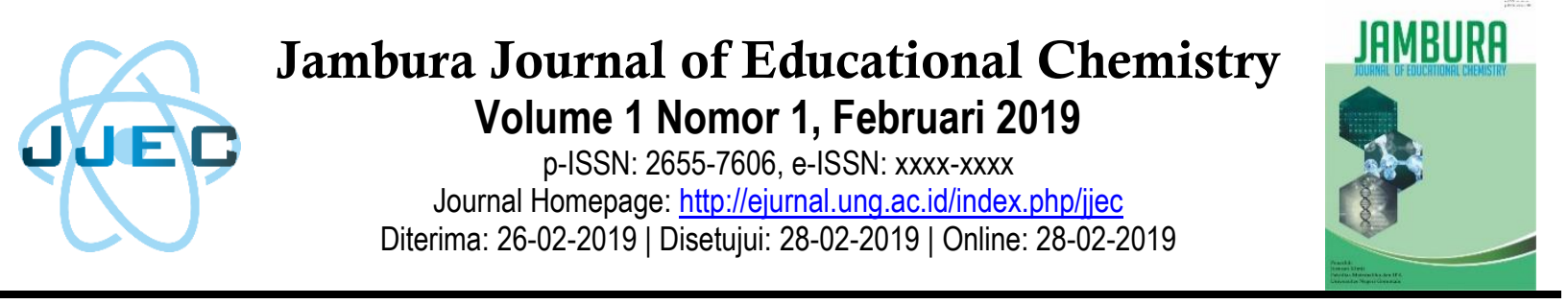

\title{
Perbedaan Hasil Belajar Kognitif Siswa Menggunakan Model Problem Based Learning dan Model Discovery Learning Pada Materi Larutan Asam dan Basa di Madrasah Aliyah Negeri Limboto
}

\author{
Hamdan Halalutu1, Ishak Isa1, Nurhayati Bialangi ${ }^{1}$ \\ 1,3Prodi Pendidikan Kimia, Jurusan Kimia, Fakultas Matematika dan IPA, Universitas Negeri Gorontalo \\ ${ }^{2}$ Prodi Kimia, Jurusan Kimia, Fakultas Matematika dan IPA, Universitas Negeri Gorontalo \\ e-mail: hamdan.h16@gmail.com
}

\begin{abstract}
Abstrak
Penelitian ini bertujuan untuk mengetahui perbedaan hasil belajar kognitif siswa menggunakan model problem based learning dan model discovery learning pada materi larutan asam dan basa di Madrasah Aliyah Negeri Limboto. Penelitian ini merupakan penelitian kuantitatif. Metode penelitian ini berupa eksperimen semu (quasi eksperiment) dengan desain nonequivalent control group design. Populasi dalam penelitian ini adalah siswa kelas XI Madrasah Aliyah Limboto. Penentuan sampel dengan teknik sampling jenuh. Teknik pengumpulan data dengan menggunakan tes, yaitu pretest dan posttest. Teknik analisis data yang digunakan adalah uji t. Berdasarkan hasil perhitungan diperoleh nilai $t_{\text {hitung }}(0,15)$ lebih besar dari $t_{\text {tabel }}(2,04)$, maka hipotesis Ho diterima dan Ha ditolak. Hal tersebut menunjukkan tidak terdapat perbedaan hasil belajar kognitif siswa menggunakan model problem based learning dan model discovery learning pada materi larutan asam dan basa di Madrasah Aliyah Negeri Limboto.
\end{abstract}

Kata Kuci: Kognitif, Problem Based Learning, Discovery, Asam Basa.

\section{PENDAHULUAN}

Ilmu kimia adalah cabang ilmu pengetahuan alam (IPA) yang mempelajari tentang struktur, komposisi, sifat dan perubahan materi serta energi yang menyertai perubaan tersebut. Dalam kehidupan sehari hari banyak yang berkaitan dengan materi dan disetiap materi itulah yang akan dipelajari dalam ilmu kimia.

Dalam dunia pendidikan khususnya pada Sekolah Menengah Atas (SMA) kimia sangatlah penting untuk dipelajari seiring dengan bekembangnya ilmu dan teknologi. Namun faktanya dilapangan kimia sangatlah sulit dipelajari siswa, karena tidak hanya dipelajari tentang teori saja akan tetapi siswa dipacuh untuk dapat merealisasikan dalam kehidupan nyata.
Rendahnya hasil belajar kimia khususnya pada materi larutan asam dan basa disebabkan pemahaman kosenp yang dimiliki siswa masih rendah dan kurang berhasilnya proses pembelajaran yang telah dilakukan. Diketahui permasalahan yang terjadi guru dan siswa dalam kegiatan belajar pada materi larutan asam dan basa adalah guru memilih model pembelajaran yang tidak sesuai dengan materi yang disajikan sehingga siswa sulit memahami materi, penyampaian materi masih dilakukan dengan metode konvensional yang menjadikan guru sebagai pusat pembelajaran (teacher centered), kurangnya referensi dan sumber belajar yang mendukung bagi siswa, kurangnya pemanfataan media pembelajaran serta sarana dan prasarana yang ada dalam sekolah. Berdasarkan permasalahan tersebut, maka 
diperlukan tindakan untuk memperbaiki produk belajar siswa agar menjadi lebih baik.

Hilmina (2011) mengemukakan pembelajaran dengan model discovery learning dapat melatih siswa untuk mendapatkan jawaban sendiri berdasarkan temuannya atau menemukan lagi sesuatu yang ditemukan. Discovery Learning adalah metode mengajar yang mengatur pengajaran sedemikian rupa sehingga anak memperoleh pengetahuan yang sebelumnya belum diketahuinya tanpa pemberitahuan langsung; sebagian atau seluruhnya ditemukan sendiri (Russefendi dalam Nurdiansyah, 2008). Untuk itu, melalui model discovery learning akan memberikan kesempatan kepada siswa untuk mengembangkan ide dan gagasannya dalam usahanya untuk memecahkan masalah.

Kelebihan model problem based learning dan model discovery learning juga didukung dengan beberapa hasil penelitian antara lain, Sibarani (2016) dengan penelitian Pengaruh penerapan model pembelajaran problem based learning terhadap peningkatan hasil belajar dan aktivitas belajar kimia siswa SMA kelas XI IPA pada pokok bahasan hidrolisis garam, berpengaruh terhadap peningkatan hasil belajar siswa. Rata-rata peningkatan hasil belajar kelas eksperimen $83,75 \%$ $\pm 0,089$ dan kelas kontrol 74,25\% $\pm 0,106$.

Berdasarkan penelitian yang telah dilaksanakan Zulfajri (2016), dapat disimpulkan dengan menggunakan model Discovery Learning pada materi Sistem Koloid yaitu sebesar 91,67\% yang menunjukkan bahwa telah mencapai ketuntasan secara individu dengan sangat baik dilihat dari hasil belajar siswa dengan menggunakan model Discovery Learning dengan media teka-teki silang.

Berdasarkan latar belekang, peneliti tertarik melakukan suatu penelitian dengan judul "Perbedaan Hasil Belajar Kognitif Siswa Menggunakan Model Problem Based Learning dan Model Discovery Learning Pada Materi larutan Asam dan Basa di Madrasah Aliyah Negeri Limboto".

\section{METODE PENELITAN}

\section{Tempat dan Waktu Penelitian}

Penelitian ini dilaksanakan di Madrasah Aliyah Negeri Limboto Kel. Kayu Merah Kab. Gorontalo Prov. Gorontalo dan dilaksanakan pada semester ganjil tahun ajaran 2017/2018

\section{Desain Penelitian}

Desain yang digunakan dalam penelitian ini adalah desain quasi experiment, dengan rancangan Nonequivalent Control Group Design pretest-posstest.

\section{Variabel Penelitian}

Variabel bebas (independen) merupakan variabel yang mempengaruhi atau yang menjadi sebab perubahannya atau timbulnya variabel terikat (dependen). Pada penelitian ini variabel bebasnya adalah model Problem Based Learing dan model discovery learning dan Variabel terikat (dependen) merupakan variabel yang dipengaruhi atau menjadi akibat, karena adanya variabel bebas (independen). Pada penelitian ini variabel terikatnya adalah hasil belajar kongnitif siswa.

\section{Populasi dan Sampel Penelitian}

Populasi dalam penelitian ini adalah seluruh siswa kelas XI semester ganjil Madrasah Aliyah Negeri Limboto tahun pelajaran 2017/2018. Sampel adalah bagian dari jumlah dan karakteristik yang dimilki oleh populasi tersebut (Sugiyono, 2015). Sampel dalam penelitian ini sebanyak 2 kelas yaitu kelas eksperimen I digunakan model problem based learning dan kelas eksperimen II digunakan model discovery learning. Pengambilan sampel dalam penelitian ini menggunakan teknik sampling jenuh. Sampling jenuh adalah teknik penentuan sampel bila semua anggota populasi digunakan sebagai sampel.

\section{Teknik Pengumpulan Data}

Teknik pengumpulan data dalam penelitian ini adalah observasi, wawancara, dan tes. Sebelum tes diberikan kepada sampel terlebih dahulu diuji validitas dan uji reliabilitas. Validitas adalah suatu ukuran yang menunjukkan tingkat kevalidan atau keaslihan sesuatu instrumen. Sebuah instrumen dikatakan valid apabila mampu mengukur apa yang diinginkan dan dapat mengungkap data dari variabel yang diteliti secara tepat. Tingggi rendahnya validitas instrumen menunjukkan sejauh mana data yang terkumpul 
tidak menyimpang dari gambaran tentang validitas yang dimaksud (Arikunto, 2010).

Hasil penelitian yang valid bila terdapat kesamaan antara data yang terkumpul dengan data yang sesungguhnya terjadi pada obyek yang diteliti (Sugiono, 2015). Untuk menghitung validitas instrument tes kongnitif siswa dengan menggunakan rumus korelasi point beserial adalah sebagai berikut (Sugiyono, 2015).

$$
\mathrm{r}_{\mathrm{pbis}}=\frac{\mathrm{Mp}-\mathrm{Mt}}{\mathrm{St}} \sqrt{\frac{\mathrm{p}}{\mathrm{q}}}
$$

Reliabilitas berhubungan dengan masalah kepercayaan. Tes dapat dikatakan mempunyai taraf kepercayaan yang tinggi jika tes tersebut dapat memberikan hasil yang tetap. Maka pengertian reliabilitas instrumen, berhubungan dengan masalah ketetapan hasil tes. Suatu instrumen memiliki tingkat reliabilitas yang memadai, bila instrumen tersebut digunakan mengukur aspek yang diukur beberapa kali hasilnya sama atau relatif sama. Semakin realibel suatu tes maka semakin yakin kita dapat menyatakan dalam hasil suatu tes mempunyai hasil yang sama ketika dilakukan tes kembali.

Pengujian releabilitas instrument dapat dilakukan secara eksternal dan internal secara eksternal pengujian dapat dilakukan dengan testretest, equivalent, dan gabungan keduanya. Secara internal dapat diuji dengan menganalis konsistensi butir butir yang ada pada instrument dengan teknik tertentu (Sugiyono, 2015). Pada penelitian ini menggunkan uji reliabilitas internal consistency. Rumus yang digunakan adalah KR.21 (Kuder Richardson) sebagai berikut.

$$
\mathrm{r}_{\mathrm{i}}=\frac{\mathrm{k}}{\mathrm{k}-1}\left(1-\mathrm{m} \frac{(\mathrm{k}-\mathrm{m})}{\mathrm{k} \cdot \mathrm{s}_{\mathrm{t}}}\right)
$$

\section{Teknik Analisis Data}

Teknik analisis data yang digunakan dalam penelitian ini adalah analisis kuantitatif. Data yang diperoleh akan dianalisis menggunakan uji perbedaan (uji t), yang bertujuan untuk melihat apakah terdapat perbedaan antara hasil belajar melalui pembelajaran model problem based learning dan pembelajaran model discovery learning.

\section{Pengujian Hipotesis Statistik}

Hipotesis statistic yang akan diuji dalam penelitian ini adalah sebagai berikut :

Ho: $\mu 1=\mu 2$

Ha : $\mu 1 \neq \mu 2$

Ketarangan :

Ho $=$ Hipotesis nol

$\mathrm{Ha}=$ Hipotesis alternative

$\mu_{1}=$ Hasil belajar siswa yang diajarkan menggunakan pembelajaran problem based learning

$\mu_{2}=$ Hasil belajar siswa yang diajarkan menggunakan pembelajaran discovery learning

Bila jumlah anggota sampel $\mathrm{n}_{1}=\mathrm{n}_{2}$ dan varian homogeny $\left(\sigma_{1}^{2}=\sigma_{2}^{2}\right)$ dapat digunakan rumus t-tes separated varian. Derajat kebebasannya $d k=n_{1}+n_{2-}$ 2 .

\section{HASIL DAN PEMBAHASAN Hasil}

Data yang diperoleh dalam penelitian ini adalah test hasil belajar kognitif yang diberikan pada siswa kelas eksperimen I menggunakan model problem based learning dan kelas eksperimen II menggunkan model discovery learning berupa pretest dan postest. Pretest diberikan sebelum perlakuan (tretment) yang bertujuan untuk mengetahui kemampuan awal siswa pada masing-masing kelompok eksperimen, sedangkan postest diberikan sesudah perlakuan (tretment) dengan tujuan dapat mengetahui sejauh mana peningkatan hasil belajar kognitif siswa pada materi larutan asam basa.

\section{Uji Prasyarat}

Uji normalitas data dalam penelitian ini menggunakan uji liliefors dengan taraf signifikansi $\alpha 5 \%(0,05)$ serta kriteria pengujian jika $\mathrm{L}_{\text {hitung }}<\mathrm{L}_{\text {tabel }}$ maka terima $\mathrm{Ho}$ data berdistribusi normal dan jika $\mathrm{L}_{\text {hitung }}>\mathrm{L}_{\text {tabel }}$ maka tolak Ho data tidak berdistribusi normal. Adapun hasil pengujian data pretes dan postest kelas eksperimen I menggunakan model problem based learning dan kelas eksperimen II menggunakan model discovery learning dapat dilihat pada tabel 1 berikut. 
Tabel 1. Hasil Pengujian Normalitas Data Pretest Dan Postest Kelas Eksperimen I dan II

\begin{tabular}{ccccc}
\hline Data & \multicolumn{2}{c}{$\begin{array}{c}\text { Kelas Eksperimen I } \\
\text { (Problem Based Learning) }\end{array}$} & \multicolumn{2}{c}{ Kelas Eksperimen II (Discovery } \\
Learning)
\end{tabular}

Berdasarkan tabel 1 data pretest kelas eksperimen I diperoleh nilai $\mathrm{L}_{\text {hitung }}=0,16$ dan pada data pretest eksperimen II $\mathrm{L}_{\text {hitung }}=0,17$, sedangkan $\mathrm{L}_{\text {tabel }}=0,21$ atau sama dengan $\mathrm{L}_{\text {hitung }}<$ $\mathrm{L}_{\text {tabel. }}$. Dapat disimpulkan kedua data pretest eksperimen I dan kelas eksperimen II data berdistribusi normal. Data postest kelas eksperimen I diperoleh nilai $\mathrm{L}_{\text {hitung }}=0,09$ dan pada data postets eksperimen II $L_{\text {hitung }}=0,13$ sedangkan $\mathrm{L}_{\text {tabel }}=0,21$ atau sama dengan $\mathrm{L}_{\text {hitung }}<\mathrm{L}_{\text {tabel }}$. Dapat disimpulkan kedua data postest kelas eksperimen I dan II berdistribusi normal.

\section{Uji Homogenitas}

Uji homogenitas dilakukan dalam rangka menguji kesamaan varians setiap kelompok data. Dalam penelitian ini uji homogenitas menggunakan uji kesamaan varians dua kelompok data adalah uji $\mathrm{F}$ (Fisher) dengan taraf signifikansi $5 \%(\alpha)$ sama dengan 0,05 dan kriteria pengujiannya terima $\mathrm{H}_{\mathrm{o}}$ jika $\mathrm{F}_{\text {hitung }}<\mathrm{F}_{\text {tabel }}$ dapat disimpulkan kedua kelompok data homogen atau memilki varians data yang sama. Hasil uji homogenitas kelas eksperimen I dan kelas eksperimen II dapat dilihat pada tabel 2 berikut.

Tabel 2. Data Hasil Uji Homogenitas Kelas Eksperimen I dan Eksperimen II

\begin{tabular}{|c|c|c|c|c|}
\hline \multirow[t]{2}{*}{ Data } & \multicolumn{2}{|c|}{$\begin{array}{c}\text { Pretest } \\
\end{array}$} & \multicolumn{2}{|c|}{ Postest } \\
\hline & Eksperimen I & Eksperimen II & Eksperimen I & Eksperimen II \\
\hline $\mathrm{N}$ & 17 & 17 & 17 & 17 \\
\hline Mean & 34,56 & 34,19 & 80,15 & 80,88 \\
\hline Varian & 112,88 & 103,11 & 225,76 & 104,84 \\
\hline$F_{\text {hitung }}$ & \multicolumn{2}{|c|}{1,09} & \multicolumn{2}{|c|}{2,15} \\
\hline $\mathrm{F}_{\text {tabel }}$ & \multicolumn{2}{|c|}{2,33} & \multicolumn{2}{|c|}{2,33} \\
\hline Kriteria & \multicolumn{2}{|c|}{ HOMOGEN } & \multicolumn{2}{|c|}{ HOMOGEN } \\
\hline
\end{tabular}

Berdasarkan tabel 2 data pretest eksperimen I dan eksperimen II didapat hasil uji homogenitas $\mathrm{F}_{\text {hitung }}=1,09$ dan taraf nyata $\alpha=0,05$, dengan $\mathrm{dk}$ pembilang $\mathrm{n}_{1}-1=16$ dan dk penyebut $\mathrm{n}_{2}-1=16$ didapat $\mathrm{F}_{\text {tabel }}=2,33$ atau $\mathrm{F}_{\text {hitung }}<\mathrm{F}_{\text {tabel. }}$. Dapat disimpulkan kedua data memiliki varians yang sama atau homogen. Sedangkan data postest kelompok eksperimen I dan eksperimen II didapat $\mathrm{F}_{\text {hitung }}=2,15$ dan $\mathrm{F}_{\text {tabel }}=2,33$ atau $\mathrm{F}_{\text {hitung }}<\mathrm{F}_{\text {tabel }}$. Dapat disimpulkan kedua kelompok data memiliki varians yang sama atau homogen.

\section{Uji Hipotesis}

Setelah hasil belajar kognitif siswa kelompok eksperimen I menggunakan model problem based learning dan eksperimen II menggunakan discovery learning diketahui berasal dari data berdistribusi normal dan memilki varians yang sama atau homogen, maka data hasil belajar kognitif siswa dilanjutkan dengan uji t rata rata 2 sampel. Uji t rata 2 sampel dilakukan bertujuan untuk membandingkan apakah kedua data hasil belajar kognitif siswa eksperimen I dan eksperimen 2 sama atau berbeda.

Kreteria pengujiannya terima hipotesis nol (Ho) jika $t_{\text {hitung }}<\mathrm{t}_{\text {tabel }}$ dan tolak Ha jika $\mathrm{t}_{\text {hitung }}>\mathrm{t}_{\text {tabel }}$ untuk taraf signifikansi $5 \%(0,05)$ dengan $\mathrm{dk}=\mathrm{n} 1$ $+\mathrm{n} 2-2$. Data hasil uji t 2 sampel eksperimen I dan eksperimen II dapat dilihat pada tabel 3 berikut: 
Tabel 3. Data Hasil Uji Hipotesis Kognitif Siswa Eksperimen I dan EksperimeII

\begin{tabular}{ccccc}
\hline Data & \multicolumn{2}{c}{ Pretest } & \multicolumn{2}{c}{ Postest } \\
\hline & Eksperimen I & Eksperimen II & Eksperimen I & Eksperimen II \\
$\mathrm{N}$ & 17 & 17 & 17 & 17 \\
Mean & 34,56 & 34,19 & 80,15 & 80,88 \\
Sgab & & 10,39 & & 12,86 \\
$t_{\text {hitung }}$ & & 0,10 & & 0,17 \\
$t_{\text {tabel }}$ & 2,04 & 2,04 \\
Kesimpulan & Tidak Terdapat Perbedaan & Tidak Terdapat Perbedaan \\
\hline
\end{tabular}

Berdasarkan tabel 3 hasil uji hipotesis diperoleh data pretest eksperimen I dan eksperimen II yaitu $\mathrm{t}_{\text {hitung }}=0,10$ pada taraf signifikansi $\alpha=5 \%(0,05)$ serta $\mathrm{dk}=\mathrm{n} 1+\mathrm{n} 2-2$ didapat nilai $\mathrm{t}_{\text {tabel }}=2,04$ atau $\mathrm{t}_{\text {hitung }}<\mathrm{t}_{\text {tabel }}$. Dapat disimpulkan data pretest kelas eksperimen I dan kelas eksperimen II tidak terdapat perbedaan. Sedangkan data postest kelas ekperimen I dan ekperimen II nilai $t_{\text {hitung }}=0,17$ dan nilai $t_{\text {tabel }}=2,04$ atau $\mathrm{t}_{\text {hitung }}<\mathrm{t}_{\text {tabel. }}$. Dapat disimpulkan data postest kelas eksperimen I dan kelas eksperimen II tidak terdapat perbedaan.

\section{Pembahasan}

Penelitian ini bertujuan untuk mengetahui adanya perbedaan hasil belajar kognitif siswa kelas eksperimen I menggunakan model problem based learning dan kelas eksperimen II dengan model discovery learning. Data yang terkumpul dalam penelitian ini berupa data pretest dan postest hasil belajar kognitif siswa pada materi larutan asam dan basa. Data tersebut dianalisis dan diuji untuk membuktikan hipotesis yang telah disusun kemudian dikaitkan dengan teori serta penelitian terdahulu sehingga dapat memberikan kesimpulan hasil penelitian.

Sebelum diberikan perlakuan pada kelas eksperimen I dengan menggunakan model problem based learning dan kelas eksperimen II menggunakan model discovery learning terlebih dahulu diberikan pretest. Pretest ini bertujuan untuk mengetahui tingkat kognitif (pengetahuan) awal dari masing-masing kelas eksperimen sama atau tidak. Dari hasil uji pretest dengan menggunakan uji normalitas dan uji homogenitas didapat bahwa kedua kelas eksperimen I dan kelas eksperimen II memiliki tingkat kognitif (pengetahuan) awal yang sama.

Setelah diketahui kedua kelompok memiliki tingkat pengetahuan awal yang sama, kemudian kedua kelompok diberikan perlakuan yang berbeda, yakni pada kelas eksperimen I digunakan model problem based learning dan pada kelas eksperimen II digunakan model discovery learning. Proses pembelajaran di kelas eksperimen I dengan menggunakan model problem based learning terdiri dari beberapa tahap yakni; orientasi siswa pada masalah, mengorganisasi siswa untuk belajar, membimbing penyelidikan individu maupun kelompok, mengembangkan dan menyajikan hasil karya, menganalisis dan mengevaluasi proses pemecahan masalah.

Sedangkan proses pembelajaran kelas eksperimen II dengan menggunakan model discovery learning tahapan yang dilaksanakan dalam penelitian ini adalah pemberian rangsangan, identifikasi masalah, pengumpulan data, pembuktian, dan menarik kesimpulan.

Setelah proses pembelajaran dari kedua kelas eksperimen I mengunakan model problem based learning dan kelas eksperimen II menggunakan model discovery learning, dilanjutkan dengan pemberian postest. Pemberian postest kelas eksperimen I menggunakan model problem based learning dan kelas eksperimen II menggunakan discovery learning bertujuan untuk mengetahui perbedaan hasil belajar siswa tingkat kognitif pada materi larutan asam dan basa kelas eksperimen I dan kelas eksperimen II.

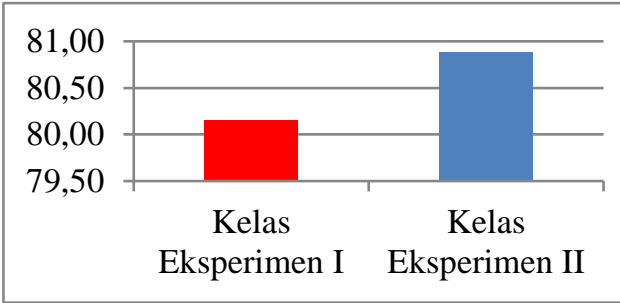

Gambar 1. Rata-Rata Hasil Postest Kelas Eksperimen I dan Kelas Eksperimen II 
Berdasarkan gambar 1 diperoleh nilai ratarata postest kelas eksperimen I menggunakan model problem based learning sebesar 80,15 dan nilai rata-rata kelas eksperimen II menggunakan model discovery learning sebesar 80,88. Dari ratarata postest kelas eksperimen I dan kelas eksperimen II dapat dilihat terdapat perbedaan hasil belajar kognitif siswa pada materi larutan asam dan basa. Untuk membuktikan hipotesis yang diajukan dalam penelitian, hasil postest yang didapat dari kelas eksperimen I menggunkan model problem based learning dan kelas eksperimen II menggunakan model discovery learning diuji dengan menggunakan uji $\mathrm{t}$ dua sampel. Uji t dua sampel pada penelitian ini dilakukan untuk mengetahui perbedaan yang signifikan antara hasil belajar kognitif siswa materi larutan asam dan basa pada kelas eksperimen I dengan menggunakan model problem based learning dan kelas eksperimen II menggunakan model discovery learning. Sebelum hasil postest dari kedua kelas eksperimen I dan kelas eksperimen II diuji menggunakn uji t dua sampel terlebih dahulu diuji persyaratan analisis data. Uji persyaratan analisis data digunakan sama dengan uji tes kemampuan awal pretest adalah uji normalitas dan uji homogenitas.

Kesimpulan dari penggunaan model problem based learning dan model discovery learning dalam penelitian adalah tidak terdapat perbedaan yang signifikan hasil belajar kognitif siswa pada materi larutan asam dan basa. Hasil penelitian ini sejalan dengan penelitian yang dilakukan Ilmiah (2016) dengan judul perbandingan model pembelajaran problem based learning dan discovery learnirning berbasis assesment for learning dengan hasil penelitian tidak terdapat perbedaan hasil belajar dan kedua model pembelajaran ini sama-sama dapat meningkatkan hasil belajar siswa.

\section{PENUTUP}

Berdasarkan hasil penelitian dan analisis data dapat disimpulkan tidak terdapat perbedaan yang signifikan antara hasil belajar kognitif siswa yang dibelajarkan dengan menggunakan model problem based learning dan model discovery learning pada materi larutan asam basa. Hal ini dibuktikan dari hasil uji hipotesis didapat nilai $\mathrm{t}_{\text {hitung }}=0,15<\mathrm{t}_{\text {tabel }}=2,04$ atau $\mathrm{t}_{\text {hitung }}<\mathrm{t}_{\text {tabel }}$ dengan $\mathrm{df}=\mathrm{n} 1+\mathrm{n} 2-1$ pada taraf signifikasi $5 \%(\alpha=0,05)$. Dengan demikian hipotesis Ho diterima dan hipotesis Ha ditolak.

Penulis menyarankan kepada guru-guru kimia maupun guru mata pelajaran umum agar dapat memilih model pembelajaran yang sesuai dengan materi dan karakteristik siswa, khususnya menggunakan model problem based learning dan model discovery learning disamping dapat mengaktifkan siswa dalam proses pembelajaran juga dapat meningkatkan hasil kognitif belajar siswa. Untuk calon guru serta mahasiswa yang ingin meneliti sangat diharapkan agar dapat mengembangkan penelitian model problem based learning dan model discovery learning untuk perbaikan mutu pendidikan kedepannya.

\section{DAFTAR PUSTAKA}

Arends, R. I. (2004). Learning To Teach. (6th Ed). New York: McGraw-Hill.

Nurdiansyah, Budi. (2008). Penggunaan Metode Penemuan untuk Meningkatkan Kemampuan Penalaran Induktif Siswa.

Sibarani, Hotmian. (2016). Pengaruh Penerapan Model Pembelajaran Problem Based Learning (Pbl) Terhadap Peningkatan Hasil Belajar Dan Aktivitas Belajar Kimia Siswa Sma Kelas Xi Ipa Pada Pokok Bahasan Hidrolisis Garam. Undergraduate Thesis. UNIMED.

Sugiyono. (2015). Metode Penelitian Kuantitatif Kualitatif dan $R \& D$. Bandung: Alfabeta.

Suharsimi, Arikunto. (2010). Dasar Dasar Evaluasi Pendidikan. Jakarta: Bumi Aksara.

Trianto, (2011). Model Pembelajaran Inovatif dan Implementasinya pada Sekolah Menengah Atas. Jakarta: Kencana Prenada Media Group.

Zulfajri, M., \& Amelia, R. (2016). Pengaruh Model Discovery Learning Dengan Media Teka-Teki Silang Terhadap Peningkatan Hasil Belajar Siswa Pada Materi Sistem Koloid. Jurnal Edukasi Kimia. 